\title{
CPUE as an index of relative abundance for nearshore reef fishes
}

\author{
Dana R. Haggarty *, Jacquelynne R. King \\ Pacific Biological Station, 3190 Hammond Bay Road, Nanaimo, BC, Canada V9T 6N7 \\ E-mail address: haggartyd@pac.dfo-mpo.gc.ca
}

This is the accepted manuscript of a paper originally published in Fisheries Research. You may find the final, formatted version at 10.1016/j.fishres.2006.05.015.

\begin{abstract}
Using density measurements derived by SCUBA diving, we have verified that research angling catch per unit of effort (CPUE) is a useful measurement of the relative abundance of nearshore reef species when the appropriate habitat is targeted. We found a strictly proportional relationship between lingcod and copper rockfish CPUE and density using a ranged major axis regression. This relationship did not hold for quillback rockfish since this study did not target their preferred depth range; nor for kelp greenling. Researchers must be aware of such limitations when using CPUE as a measure of relative abundance.
\end{abstract}

\section{Introduction}

The use of catch per unit effort (CPUE) as a measure of relative fish abundance is a common index used in stock assessment, whether calculated from commercial or recreational fisheries data or from research survey data. CPUE is often considered to be biased and not strictly proportional to abundance (Harley et al., 2001). Catch rates may remain high even if abundance decreases, a situation termed hyperstability, because of increases in fishing efficiency (catchability), changes in the behaviour of fishers (Gillis and Peterman, 1998; Cox et al., 2002), or due to fish behaviours such as hyperaggregation (Rose and Kulka, 1999) and habitat selection (Fréon et al., 1993). Commercial and recreational fishery data will often have bias due to fishing efficiency and fisher behaviour. These factors can, to some degree, be controlled in research data by applying standardized methods that include pre-determined fishing durations, locations and gear.

One of the difficulties in investigating the relationship between abundance and CPUE is obtaining a measure of abundance that does not rely on fishing data. Richards and Schnute (1986) explored the relationship between nearshore reef fish abundance and CPUE using fish counts made with a submersible research vessel and catch and effort data from a research angling survey. They found a strictly proportional relationship between fish density and CPUE for quillback rockfish (Sebastes maliger), the most abundant species in their survey. However, less abundant species such as lingcod (Ophiodon elongatus) and copper rockfish (S. caurinus), were too scarce to permit the nature of the relationship between density and CPUE to be determined. In their study, the submersible could only adequately sample depths greater than $40 \mathrm{~m}$ (Richards and Schnute, 1986). Previous research shows that lingcod and copper rockfish catch rates are higher for depths less than $25 \mathrm{~m}$ than for depths from 26 to $50 \mathrm{~m}$ (Haggarty and King, 2004, 2005).

Richards and Cass (1987) also found that catch rates of these species decreased below $40 \mathrm{~m}$; therefore, the submersible survey by Richards and Schnute (1986) likely did not target these species' preferred depth range. 
We revisit the topic of the relationship between CPUE and nearshore reef fish abundance using fish counts based on SCUBA dive surveys and research angling survey catch and effort data. Dive survey density estimates may provide a better estimate of fish abundance than those made with subermersible research vessels or remotely operated vehicles (ROV) because divers have the ability to search crevices and among boulders to detect fish. Views into crevices and under rocks are not possible with submersible research vessels or ROVs and it is likely that fish counts using these methods underestimate actual fish abundance. In addition, our sur- vey focuses on shallower depths than Richards and Schnute (1986) in order to sample habitat preferred by lingcod and copper rockfish. We compared the CPUE of lingcod, copper rockfish, quillback rockfish and kelp greenling (Hexagram- mos decagrammus) from the research angling to the density of these species obtained by visual counts using SCUBA divers. We assume density estimates from the dive survey to be indicative of the true abundance of these species.

\section{Methods}

This study took place between 27 September and 15 October 2004. All diving and fishing activities were conducted off a $7 \mathrm{~m}$ aluminium boat equipped with a depth sounder, global positioning system (GPS) and laptop computer with the navigational software Nobeltech ${ }^{\circledR}$. Eight study sites were selected in the Strait of Georgia (Fig. 1) based on their reef fish catch rates in previous research angling surveys with the intent of sampling sites that represented a range from low to high catch rates (Haggarty and King, 2004, 2005).

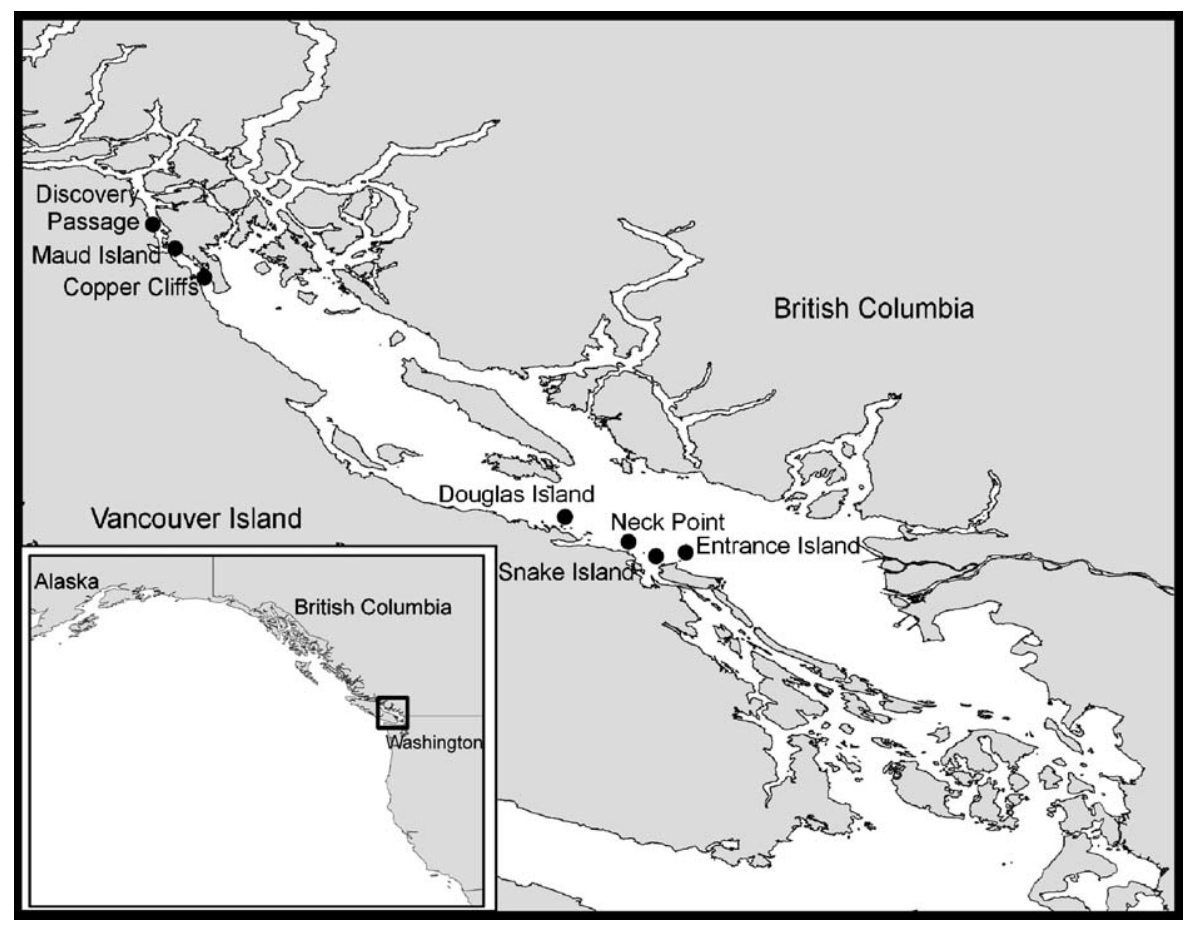

Fig. 1. Location of sampling sites in the Strait of Georgia, BC, Canada.

\section{Density estimates}

SCUBA divers counted all large reef fishes encountered within a circular plot with a radius of $10 \mathrm{~m}$. This plot method is also during lingcod egg mass surveys which is also used to estimate the density of large 
reef fishes (Haggarty et al., 2005). We completed five plots per sampling site with the exception one site, Neck Reef, which was too small to accommodate more than two plots. The mean depth at the center of the plots was $12 \mathrm{~m}$ and the minimum and maximum depth of the plots ranged between 5 and $20 \mathrm{~m}$ (Table 1). Given that catch rates for lingcod, kelp greenling and copper rock- fish decline below $25 \mathrm{~m}$, we are confident that we covered an appropriate depth range. The percent coverage of algae (Agarum sp. plus Nereocystis luetkeana) in each plot was recorded (Table 1) and was not dense enough to obstruct the movement of the $10 \mathrm{~m}$ plot line. The centre of each plot was marked with a cannon ball attached to a line and dive float, and was mapped using GPS and Nobeltech ${ }^{\circledR}$. Plots were selected for suitable rocky reef habitat using the depth sounder to assess relief and hardness of the bottom, and were orientated along the same depth contour. One diver controlled the $10 \mathrm{~m}$ plot line which was attached to the center cannon ball while the other diver searched consecutive wedges of the plot. Divers used lights to search for fishes in crevices and cracks and among flora. Divers compared the size of the cop- per rockfish and quillback rockfish to a $15 \mathrm{~cm}$ mark on their slates in order to classify rockfish as less than or greater than $15 \mathrm{~cm}$ in length. Previous research showed that only rockfish greater than $15 \mathrm{~cm}$ are caught on the research angling gear (Haggarty and King, 2005). For each site, the density of ling- cod, kelp greenling, copper rockfish and quillback rockfish greater than $15 \mathrm{~cm}$ was calculated as the total number of fish counted in all plots divided by the total area searched.

\section{CPUE from research angling}

Table 1

The sampling date for SCUBA fish density estimates by site

\begin{tabular}{|c|c|c|c|c|c|c|c|c|}
\hline \multirow[t]{2}{*}{ Site } & \multirow[t]{2}{*}{ Date } & \multirow[t]{2}{*}{$N$} & \multirow{2}{*}{$\begin{array}{l}\text { Depth } \\
\text { Mean (range) }\end{array}$} & \multirow{2}{*}{$\begin{array}{l}\text { Algae, \% cover } \\
\text { Mean (S.D.) }\end{array}$} & \multicolumn{4}{|c|}{ Fish density (fish per $100 \mathrm{~m}^{2}$ ) } \\
\hline & & & & & $\begin{array}{l}\text { Lingcod } \\
\text { Mean (S.D.) }\end{array}$ & $\begin{array}{l}\text { Copper } \\
\text { Mean (S.D.) }\end{array}$ & $\begin{array}{l}\text { Quillback } \\
\text { Mean (S.D.) }\end{array}$ & $\begin{array}{l}\text { Kelp greenling } \\
\text { Mean (S.D.) }\end{array}$ \\
\hline Copper & 2004-10-04 & 5 & $12.1(8-15)$ & $2.0(2.7)$ & $2.4(1.7)$ & $1.9(1.7)$ & $7.1(1.2)$ & $1.6(1.1)$ \\
\hline Discovery & $2004-10-03$ & 5 & $13.3(10-17)$ & $2.4(5.4)$ & $2.1(0.5)$ & $9.2(4.8)$ & $2.6(0.9)$ & $1.5(1.0)$ \\
\hline Maud & 2004-10-03 & 5 & $9.8(7-14)$ & $26.0(32.3)$ & $1.3(0.4)$ & $1.8(1.9)$ & $2.2(1.5)$ & $1.1(0.9)$ \\
\hline Douglas & 2004-09-27 & 5 & $11.1(9-14)$ & $1.0(2.2)$ & $0.2(0.2)$ & $1.7(2.2)$ & $2.7(1.3)$ & $1.2(0.8)$ \\
\hline Entrance & 2004-10-01 & 5 & $13.4(11-15)$ & $9.0(14.7)$ & $0.5(0.5)$ & $2.6(2.9)$ & $0.0(-)$ & $1.0(0.4)$ \\
\hline Round & $2004-09-28$ & 5 & $10.7(10-13)$ & $33.0(19.2)$ & $0.0(-)$ & $1.3(0.8)$ & $1.0(0.7)$ & $0.6(0.6)$ \\
\hline Snake & 2004-09-30 & 5 & $12.9(12-15)$ & $32.0(25.9)$ & $0.5(0.6)$ & $2.9(2.5)$ & $1.0(1.0)$ & $1.3(0.8)$ \\
\hline Neck & $2004-10-15$ & 2 & $15.0(10-19)$ & $77.5(3.5)$ & $0.5(0.7)$ & $5.3(1.6)$ & $4.5(1.4)$ & $1.1(0.7)$ \\
\hline
\end{tabular}

Information for each site includes: the number of plots surveyed $(N)$; the mean depth $(\mathrm{m})$ and range surveyed; the estimated mean (and standard deviation) proportion (\%) of the area surveyed by divers that was covered by macroalgae (Agarum sp. and Nereocystis leutkeana); and the mean (and standard deviations) fish density (fish per $100 \mathrm{~m}^{2}$ ) from SCUBA observations for the $N$ plots at each site.

All fishing was conducted using trolling rods and reels using $12 \mathrm{~cm}$ frozen herring as bait, and occurred after fish counts by divers were completed. Similar angling method- ology to Richards and Schnute (1986) was used to derive CPUE and is outlined in detail in Haggarty and King (2005). Briefly, each person fished at each site for a designated amount of time and recorded all fish caught. Fishing time was halted when a fish was caught or whenever the gear was reeled in or hooked to the bottom. We were able to fish directly over each dive plot, since the center of each plot was mapped with navigational software. Three people fished at once for an accumulated fishing time of 60-75 min per site, except at the Neck Reef, which was only fished for $30 \mathrm{~min}$ (Table 2). The boat operator used a depth sounder and navigational software to ensure that fishing occurred at the same depth range as each dive plot and ensured that equal fishing time (approximately $12 \mathrm{~min}$ ) was spent above each plot. Fishing was halted when the boat floated outside the target range of the plot. A catch was recorded if a fish was brought to the surface and could be identified to species. Fork or total lengths of all fishes landed were measured to the nearest millimeter. CPUE (fish per hour) for lingcod, kelp greenling, copper rockfish and quillback rockfish greater than $15 \mathrm{~cm}$ was calculated for each site as the total number of fish caught by all anglers divided by the total fishing time of all anglers. 
Table 2

Catch per unit effort (CPUE) (fish per hour) for lingcod, copper rockfish, quillback rockfish and kelp greenling for each site presented with the date fished; the time fishing commenced; the total time fished (time summed for all three fishers); the sea state (1: calm, 2: ripple); and the minimum, maximum and modal fishing depth (m)

\begin{tabular}{|c|c|c|c|c|c|c|c|c|c|c|c|}
\hline \multirow[t]{2}{*}{ Site } & \multirow[t]{2}{*}{ Date } & \multirow[t]{2}{*}{ Start time } & \multirow{2}{*}{$\begin{array}{l}\text { Total time } \\
\text { (min) }\end{array}$} & \multirow[t]{2}{*}{ Sea state } & \multicolumn{3}{|l|}{ Depth (m) } & \multicolumn{4}{|c|}{ CPUE (fish per hour) } \\
\hline & & & & & Minimum & Maximum & Modal & Lingcod & Copper & Quillback & Kelp greenling \\
\hline Copper & $2004-10-06$ & $15: 38$ & 75 & 1 & 5 & 12 & 19 & 3.2 & 0.8 & 0.0 & 2.4 \\
\hline Discovery & $2004-10-06$ & $13: 36$ & 60 & 1 & 8 & 20 & 12 & 13.2 & 12.2 & 2.0 & 3.1 \\
\hline Maud & 2004-10-06 & $11: 48$ & 75 & 1 & 5 & 20 & 12 & 2.4 & 3.2 & 1.6 & 0.8 \\
\hline Douglas & $2004-10-12$ & 09:50 & 62 & 1 & 5 & 17 & 11 & 1.0 & 0.0 & 0.0 & 1.9 \\
\hline Entrance & $2004-10-12$ & $12: 05$ & 60 & 1 & 5 & 13 & 8 & 3.0 & 0.0 & 0.0 & 3.9 \\
\hline Round & $2004-10-13$ & $09: 28$ & 61 & 1 & 5 & 16 & 11 & 0.0 & 2.0 & 0.0 & 0.0 \\
\hline Snake & $2004-10-12$ & $13: 21$ & 62 & 1 & 5 & 16 & 8 & 2.9 & 2.9 & 0.0 & 0.0 \\
\hline Neck & $2004-10-14$ & 09:03 & 30 & 2 & 14 & 20 & 18 & 2.0 & 10.0 & 46.0 & 4.0 \\
\hline
\end{tabular}

Regression analyses

Because both the dependent variable, CPUE (fish per hour) and the independent variable, density (fish per $100 \mathrm{~m}^{2}$ ), have associated variability, we used a Model II regression to determine the relationship between CPUE and fish density totalled for all dive plots per site (Ricker, 1973; Laws and Archie, 1981). Since the fishing was conducted by drifting overtop of all dive plots, site density was calculated as total number of fish counted by total area searched summed across plots for each site. Prior to regression analysis, we used the Shapiro-Wilk test to examine whether the data con- formed to a normal distribution and then used a square root transformation to meet the assumptions of normal distribution and homogenous variance (Sokal and Rohlf, 1995). We applied the square-root transformation to both variables in order to preserve the relationship between the $y$ and $x$ variables (Carrol and Ruppert, 1988). In order to make the two variables dimensionally homogenous we ranged the data and performed a ranged major axis regression (RMA) (Legendre and Legendre, 1998). Wecalculated 95\% confidence intervals around the RMA slope to examine significance (Sokal and Rohlf, 1995). Legendre and Legendre (1998) state that confidence intervals can be used to compare the slope to hypothetical values of interest such as 1 or 0 . We also provide the ordinary least squares (OLS) regression $F$ statistic and probability for comparison. OLS regression and Shapiro-Wilk test were performed with Statistix 7.0 (Analytical Software, 2000).

\section{Results}

Lingcod, copper rockfish and quillback rockfish densities varied by site (Table 1), but there was no difference among sites in kelp greenling density (Table 1). Lingcod and cop- per rockfish catch rates were highest at Discovery but Neck Reef also had high rockfish catch rates. There were no significant differences among sites in the size of any species caught during fishing. The length of fish observed while diving was not estimated. The mean length (and standard deviation) of lingcod, copper rockfish, quillback rockfish and kelp green- ling caught was $45.9 \mathrm{~cm}$ (10.2), $30.5 \mathrm{~cm}$ (4.4), $29.3 \mathrm{~cm}$ (4.1) and $37.5 \mathrm{~cm}(8.5)$, respectively. The minimum size of copper rockfish $(21.0 \mathrm{~cm})$ and quillback rockfish $(17.8 \mathrm{~cm})$ caught on hook and line was greater than the $15 \mathrm{~cm}$ size category we used in the visual survey. Numerous copper rockfish and quillback rockfish in the less than $15 \mathrm{~cm}$ category were counted during the dive survey. The OLS regression of CPUE on fish density showed significant regression lines for both lingcod and copper rockfish (Table 3). The slope of the ranged major axis regression was, in both cases, close to 1 with relatively tight $95 \%$ confidence intervals; however the confidence interval around the slope was greater for copper rockfish than it was for lingcod (Table 3). The $y$-intercept of the RMA slope for these two species was also close to zero. Consequently, the data from these two species agrees with a model of strict 
proportionality. Although quillback rockfish CPUE and density had a RMA slope of 1.5, the confidence interval around the slope was large, and the OLS regression was not statistically significant (Table 3).

Kelp greenling CPUE and density had the worst fitting RMA line with a slope of 1.9 and a wide confidence interval (0.8-17.4) (Table 3).

Table 3

The slope $\left(b_{R M A}\right), 95 \%$ confidence intervals and the equation of the line of the ranged major axis (RMA) regression between CPUE and density

\begin{tabular}{|c|c|c|c|c|c|c|}
\hline \multirow[t]{2}{*}{ Species } & \multirow[t]{2}{*}{$b_{\mathrm{RMA}}$} & \multicolumn{2}{|c|}{$95 \% \mathrm{CI}$} & \multirow[t]{2}{*}{ Equation of line } & \multirow[t]{2}{*}{$F$} & \multirow[t]{2}{*}{ OLS, $P$ level } \\
\hline & & Lower & Upper & & & \\
\hline Lingcod & 0.8 & 0.2 & 2.4 & $y=0.8 x+0.02$ & 10.48 & $0.02^{*}$ \\
\hline Copper & 1.1 & 0.4 & 4.90 & $y=1.1 x+0.1$ & 9.09 & $0.02^{*}$ \\
\hline Quillback & 1.5 & 0.5 & 8.4 & $y=1.5 x-0.6$ & 0.94 & 0.37 \\
\hline Kelp greenling & 1.9 & 0.8 & 17.4 & $y=1.9 x-0.6$ & 1.26 & 0.30 \\
\hline
\end{tabular}

The $F$ statistic and probability from the ordinary least squares (OLS) regression are also provided.

* Significant at 0.05 level.

\section{Discussion}

Using SCUBA density measurements, we have verified that research angling CPUE is a useful measurement of the relative abundance of nearshore reef species when targeting appropriate depth and habitat. We assume that the density measurements made by SCUBA divers in this study provide a good estimate of the true abundance of nearshore reef fish species. Richards and Schnute (1986) remark that since submersibles do not have the ability to examine cracks and crevices unless they pass directly over them, fish density estimates from submersible surveys should be considered minimum estimates.

Conversely, we made a concerted effort to search for fish in cracks and crevices and recorded the position of the fish at sighting. SCUBA surveys are also known to underestimate fish counts but bias tends to be greatest for cryptic species and highly abundant fishes (Sale and Douglas, 1981; Brock, 1982). The four fish species considered here are relatively large and visible, but do not usually aggregate in large groups; therefore, we have confidence that our observed fish density provides a reasonable abundance estimate for these species.

Richards and Schnute (1986) compared catch rates from the research angling surveys to density data collected on submersible dives and modeled the relationship between density and CPUE. They discuss various cases their model is able to describe, including strict proportionality, no relationship, and modifications of proportionality at low and high density (Richards and Schnute, 1986). They found that quillback rockfish, the dominant species observed by the submersible and most frequently caught while angling over the $41-70 \mathrm{~m}$ depth interval, demonstrated a strictly proportional relation- ship between CPUE and density. Copper rockfish and lingcod observations from the submersible were too low and variable to model separately, so they combined them using a general fish category and were not be able to find a significant fit to their model (Richards and Schnute, 1986).

Using SCUBA diving rather than submersible counts allowed us to sample the shallower depth distribution of ling- cod and copper rockfish. We found a strictly proportional relationship between catch rates and density for lingcod and copper rockfish over the depth range sampled. Both ling- cod and copper rockfish CPUE and density had a significant linear relationship using the ranged major axis regression which allows for variation around both variables (Legendre and Legendre, 1998). Conversely, the SCUBA survey and shallow depth interval fished did not adequately sample the depth range of quillback rockfish (subtidal to $274 \mathrm{~m}$ ) (Love et al., 2002). Therefore, the strictly proportional relationship found by Richards 
and Schnute (1986) for quillback rockfish was not reproduced here. There was no correlation observed between kelp greenling density and CPUE, perhaps because kelp greenling are less susceptible to the bait used in the research angling. Kelp greenling have smaller mouths than the other species and tend to nibble at the bait rather than swallowing it whole.

Our research, coupled with Richards and Schnute (1986), indicates that CPUE derived from standardized surveys can be used to measure relative abundance. Although they can- not be easily translated into a fish density, they can be used to monitor, in a relative sense, if a fish population is increasing, decreasing or remaining constant. Researchers need to be aware of limitations such as susceptibility to gear, here illustrated by the lack of correspondence between kelp greenling density and CPUE; or targeted habitat, here illustrated by the difference in our results for quillback rockfish, lingcod and copper rockfish from Richards and Schnute's (1986) results when a different depth range is targeted.

As a research tool, hook and line surveys are probably a cost effective and simple way to obtain a relative abundance measure for certain species, such as copper rockfish and lingcod and quillback rockfish in deeper water (Richards and Schnute, 1986). Biological samples (length, weight, sex, maturity, stomach contents) can also be collected using this method. SCUBA surveys, or other visual survey techniques such as remotely operated vehicles and submersible surveys, are more time consuming and expensive but do offer the advantages of monitoring species and life history stages that are not susceptible to hook and line gear, and have the ability to also collect additional data on behaviour and habitat use. Visual surveys may not be as susceptible to environ- mental variables (i.e. time of day, tide, weather) or behaviour (competition or satiation) that may affect catch rates. Visual surveys are also non-lethal, which is can be an advantage in areas where there are conservation concerns and for species, such as rockfishes, that do not have high survival rates after being released.

\section{Acknowledgements}

Thank you to V.Hodes, P. Winchell, K. Mathias, L. Mac- Dougall and J. Martin for their assistance in the field.

\section{References}

Analytical Software, 2000. Statistix 7.0 for Windows.

Brock, R.E., 1982. A critique of the visual consensus method for assessing coral reef fish populations. Bull. Mar. Sci. 32, 269-276.

Carrol, R.J., Ruppert, D., 1988. Transformation and Weighting in Regres- sion. Chapman and Hall, New York.

Cox, S.P., Beard, T.D., Walters, C., 2002. Harvest control in open-access sport fisheries: hot rod or asleep at the wheel? Bull. Mar. Sci. 70, 749-761.

Fréon, P., Gerlotto, F., Misund, O.A., 1993. Consequences of fish behaviour for stock assessment. ICES Mar. Sci. Symp. 196, 190- 195.

Gillis, D.M., Peterman, R.M., 1998. Implications of interference among fishing vessels and the ideal free distribution to the interpretation of CPUE. Can. J. Fish. Aquat. Sci. 55, 37-46.

Haggarty, D.R., King, J.R., 2004. Hook and line survey of lingcod (Ophiodon elongatus) and rockfish (Sebastes sp.) stocks in south- ern Strait of Georgia (statistical areas 17, 18 and 19), October 2003. Can. Tech. Rep. Fish. Aquat. Sci. 2533, 38.

Haggarty, D.R., King, J.R., 2005. Hook and line survey of lingcod (Ophiodon elongatus) and rockfish (Sebastes spp.) in northern Strait of Georgia (statistical areas 13, 14, 15 and 16), 
June 14-July 9, 2004. Can. Tech. Rep. Fish. Aquat. Sci. 2590, 57.

Haggarty, D.R., King, J.R., Hodes, V.R., 2005. Lingcod egg mass and reef fish density SCUBA survey in the Strait of Georgia, February 19-March 11, 2005. Can. Data Rep. Fish. Aquat. Sci. 1161, iv + 16. Harley, S.J., Myers, R.A., Dunn, A., 2001. Is catch-per-unit-effort portional to abundance? Can. J. Fish. Aquat. Sci. 58, 1760-1772.

pro-

Laws, E.A., Archie, J.W., 1981. Appropriate use of regression analysis in marine biology. Mar. Biol. 65, 13-16.

Legendre, P., Legendre, L., 1998. Numerical Ecology. Developments in Environmental Modelling, vol. 20., second English ed. Elsevier, Ams- terdam.

Love, M.S., Yoklavich, M., Thorsteinson, L., 2002. The Rockfishes of the Northeast Pacific. University of California Press, Los Angeles, CA.

Richards, L.J., Cass, A.J., 1987. 1986 research catch and effort data on nearshore reef-fishes in British Columbia Statistical Areas 12,13 and 16. Can. Man. Rep. Fish. Aquat. Sci. 1903, 119.

Richards, L.J., Schnute, J.T., 1986. An experimental and statistical approach to the question: is CPUE an index of abundance? Can. J. Fish. Aquat. Sci. 43, 1214-1227.

Ricker, W.E., 1973. Linear regression in fishery research. J. Fish. Res.

Board Can. 30, 409-434.

Rose, G.A., Kulka, D.W., 1999. Hyperaggregation of fish and fisheries: how the catch-perunit-effort increased as the northern cod (Gadus morhua) declined. Can. J. Fish. Aquat. Sci. 56 (Suppl. 1), 118-127. Sale, P.F., Douglas, W.A., 1981. Precision and accuracy of visual census techniques for fish assemblages on coral patch reefs. Environ. Biol.

Fish. 6, 333-339.

Sokal, R.R., Rohlf, F.J., 1995. Biometry, third ed. W.H. Freeman and Company, New York. 